Check for updates

Cite this: RSC Adv., 2017, 7, 35411

\title{
Formation and properties of HMX-based microspheres via spray drying
}

\author{
B. Y. Ye, (D) $\dagger^{a}$ C. W. An, (ID $\dagger^{* a b}$ J. Y. Wang $\left(\mathbb{D}{ }^{* a b}\right.$ and X. H. Geng ${ }^{c}$ \\ Herein, we report a facile strategy to prepare a novel HMX-based microspheres by coating a layer of \\ energetic binders on HMX. HMX-based microspheres were synthesized and compared by different \\ dissolution methods by spray dying. The HMX-based composites were also prepared by a water- \\ suspension method. The formation mechanism of the hollow structure and core-shell structure is \\ proposed. The as-prepared HMX/NC/GAP microspheres synthesized by suspension spray drying were \\ found to possess a solid core-shell structure, display a $\beta$-form, lower impact sensitivity and higher \\ energy performance.
}

Received 6th March 2017

Accepted 10th July 2017

DOI: $10.1039 / \mathrm{c} 7 \mathrm{ra02737k}$

rsc.li/rsc-advances

prepare composites. ${ }^{11}$ Over the past few years, several kinds of composite energetic materials have been prepared by spray drying method. These materials mainly include CL-20/EPDM, ${ }^{12}$

HMX (octahydro-1,3,5,7-tetranitro-1,3,5,7-tetrazocine), a typical nitramine explosive, has been widely used as the main component in various munitions and propellants. ${ }^{1-3}$ High energy output and destructibility, owing to the cyclic structure of nitramine, make it a high energy density material. It is expected to improve the specific impulse, burning rate, detonation pressure and detonation velocity performance of munitions. ${ }^{4}$ However, the most serious limitation for its application is the high sensitivity towards impact, friction, shock wave, and electric spark. Therefore, considerable work has been done to design and synthesize insensitive energetic compounds and composites. ${ }^{5-7}$ Current techniques for desensitization of high explosives mainly include ultrafine, crystal control, cocrystal $^{8}$ and particle coating technology. ${ }^{9}$ Among these technologies, particle coating is considered to be a popular method to reduce the sensitivities of explosives because it can break through the restriction for the incapability of changing the inherent molecules or components compared with other approaches. ${ }^{4}$ In addition, molding, mechanical and thermal properties can be adjusted with the regulation of polymers in the composites. However, the surface coverage and mechanical strength are proved relatively poor by the widely used water suspension and kneading., ${ }^{4,10}$ Thus, a novel coating technique to fabricate energetic coated samples should be explored. Because of the convenience, easy control over the stoichiometry and homogeneity, spray drying is an important technology to

\footnotetext{
${ }^{a}$ School of Environment and Safety Engineering, North University of China, Taiyuan, Shanxi, 030051, China.E-mail: anchongwei@yeah.net; wjywjy67@163.com

${ }^{b}$ Shanxi Engineering Technology Research Center for Ultrafine Powder, North University of China, Taiyuan, Shanxi, 030051, China

${ }^{c}$ College of Resources and Environmental Engineering, Binzhou University, Binzhou, Shandong, 256603, China

$\dagger$ These authors contributed equally to this work.
} vitonA ${ }^{16}$ and $\mathrm{RDX} / \mathrm{PVAC}^{17}$ Among these polymers mentioned above, most of them are inert, which is the primary reason for the restriction of further energy release rate. Furthermore, the formulation composition of propellants can be changed. In order to eliminate the negative impact, the ingredients of propellants were selected to coat the nitramine explosives. ${ }^{18}$ Thus, composite materials such as $\mathrm{HMX} / \mathrm{NC}^{19}, \mathrm{RDX} / \mathrm{NC} / \mathrm{C}-1$ (ref. 20), RDX/GAP ${ }^{21}$ were prepared. As energetic binder, nitrocellulose (NC) is one of the important components, which can improve the energy output of composites. Nevertheless, NC is a semi-rigid polymer with bad thermoplastic property and high glass transition temperature. It will cause embrittlement and affect the mechanical properties of propellants if NC is used to coat nitramine explosives. In propellant formulation, the binder plays an important role as the base body and skeleton. Using some new types of energetic binders, the propellants can be endowed with perfect energy performance and good mechanical properties. Glycidyl azide polymers (GAP) are promising candidates for energetic binders due to its high energy, lowcharacteristic signal, and low mechanical sensitivity. It is able to meet the high performance requirements of propellants. But GAP could not be used to coat explosives alone due to its poor formability, which adversely affects the final products. If combined NC with GAP as the composite binders, GAP can be imbedded in the NC matrix, leading to an increased properties of the binders. Thus, in our previous research, we prepared $\mathrm{RDX} / \mathrm{NC} / \mathrm{GAP}$ energetic composite in which RDX particles were coated successfully by NC and GAP through water-suspension method. However, this method is not the best choice due to the inferior morphology and large particle obtained by watersuspension method. Such unfavorable factors may cause poor 
desensitization effect and structural instability in practical application. $^{22}$

Spray drying is an effective method to prepare spherical particles. In this study, a novel HMX-based microsphere coated with NC and GAP was prepared by spray drying in two kind of way. The formation process of HMX-based microsphere has been studied and analyzed in detail. Given this, improved control of the HMX-based microsphere is possible, which could lead to HMX-based composites with optimal performance ultimately.

\section{Experimental sections}

\subsection{Materials}

Raw HMX was produced by Gansu Yinguang Chemical Industry Co., Ltd (Baiyin city, Gansu province, P.R. China). NC (12\% N, industrial grade) was produced by Foshan Junyuan Chemical Co., Ltd (Foshan city, Guangdong province, P.R. China). GAP, number-average molecular weight $\left(M_{\mathrm{n}}\right)=3502$, with hydroxyl value of $30.41 \mathrm{mg} \mathrm{KOH} \mathrm{g}{ }^{-1}$, was produced by Luzhou North Chemical Industry Co., Ltd (Luzhou city, Sichuan province, P.R. China). Acetone, ethyl acetate, dimethyl sulfone (DMSO) was produced by Tianjin Tianda Chemical Co., Ltd (Tianjin city, P.R. China).

\subsection{Recrystallization of HMX}

Among four crystal structures ( $\alpha-, \beta-, \gamma$ - and $\delta$-) of HMX obtained at normal pressure and temperature, $\beta$-HMX has the largest density and best thermal stability. Preparing high quality $\beta$ HMX crystals is validated to be an effective way to reduce the sensitivity of HMX. ${ }^{23}$

The recrystallization procedure of HMX is similar to that of RDX, reported in our earlier research. ${ }^{18}$ The experimental process was described as follows. $20 \mathrm{~g}$ raw HMX was dissolved in $50 \mathrm{~mL}$ dimethyl sulfoxide in a $100 \mathrm{~mL}$ beaker to make a saturated solution. The HMX solution was sprayed $800 \mathrm{~mL}$ distilled water through a nozzle assisted by vacuum pump, while the solution was stirred at a certain rate for 5 minutes. After being filtered and washed, the obtained HMX was dried under a freeze dryer for further experiments.

\subsection{Synthesis of HMX/NC/GAP microspheres}

Two samples of HMX-based microspheres were synthesized in different dissolution ways by spray dying, as summarized in the following. The experimental apparatus is shown in Fig. 1.

(I) The sample was prepared by co-solution spray drying (labeled as sample-1): HMX, NC and GAP were dissolved in acetone to form a uniform solution (Fig. 1(4)). The solution was fed to the atomizers using a peristaltic pump (Fig. 1(3)) at 7.5 $\mathrm{mL} \mathrm{min}^{-1}$. The flow rate of inlet dry gas was $347 \mathrm{~L} \mathrm{~h}^{-1}$ (Fig. 1(1)). The inlet dry gas $\mathrm{N}_{2}$ temperature was kept at $60{ }^{\circ} \mathrm{C}$.

(II) The sample was produced by suspension spray drying (labeled as sample-2): The binders NC and GAP were dissolved into ethyl acetate to form a solution with the concentration of 5 wt\%. HMX was added directly into the binders solution with stirring to generate a stable suspension. The inlet dry gas $\mathrm{N}_{2}$

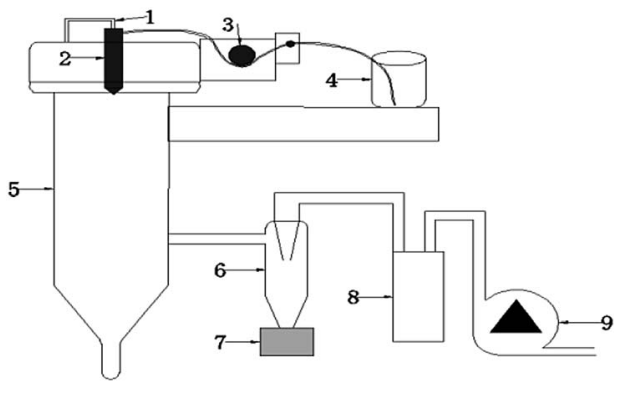

Fig. 1 Experimental apparatus of spray drying: (1) compressed air collection; (2) two-fluid spray nozzle; (3) peristaltic pump; (4) suspension liquid; (5) spray cylinder; (6) cyclone separator; (7) product collecting container; (8) outlet filter; (9) air purge unit.

temperature was kept at $80^{\circ} \mathrm{C}$. The other processing parameters were consistent with (I).

The produced particles (sample-1 and sample-2) were separated from the drying gas flow with a cyclone separator (Fig. 1(6)) and collected in a product collecting container (Fig. 1(7)). The spray dryer we used is B-290 (B-290, Switzerland, nozzle size: $0.5 \mathrm{~mm}$ ).

(III) To compare, the sample was prepared by watersuspension marked as sample-3. The detailed preparing process is consistent with our earlier research. ${ }^{18}$

\subsection{Characterization}

The surface morphology, mean size, and size distribution of the as-prepared HMX-based microspheres were characterized using scanning electronic microscopy (SEM, SU-8020, Hitachi, Japan), laser diffraction particle size analyzer (90 PLUS, America) and transmission electron microscopy (TEM, Tecnai G2 F20, FEI, America).

DX-2700 X-ray diffraction (XRD, Dandong Haoyuan Corporation, Liaoning, China) was used to analyze the crystal form of as-prepared samples at a voltage of $40 \mathrm{kV}$ and a current of $30 \mathrm{~mA}$ using $\mathrm{Cu}-\mathrm{K} \alpha$ radiation at $\lambda=1.5418 \AA$.

Fourier transform infrared (FT-IR) spectra were characterized by a Nicolet FT-IR 8700 Thermo (Waltham, MA, United States) with a wave number resolution of $4 \mathrm{~cm}^{-1}$ and a single average of 32 scans at number temperature.

Thermal analysis was performed on a differential scanning calorimeter (DSC-131, France setaram Corporation, Shanghai, China) at heating rates of $10{ }^{\circ} \mathrm{C} \mathrm{min}^{-1}$.

The impact sensitivity was tested with a home-built Type 12 drop hammer apparatus. The special height $\left(H_{50}\right)$ represents the height from which $2.500 \pm 0.002 \mathrm{~kg}$ drop hammer will result in an explosive event in $50 \%$ of the trials. In each determination, 25 drop tests were made to calculate the $H_{50}$.

\section{Results and discussion}

\subsection{Morphological and size characterization}

The morphology and structure of the as-prepared samples were probed by SEM, TEM and laser diffraction particle size analyzer, and the results are illustrated in Fig. 2 and 3. Fig. $2 a$ and b show 

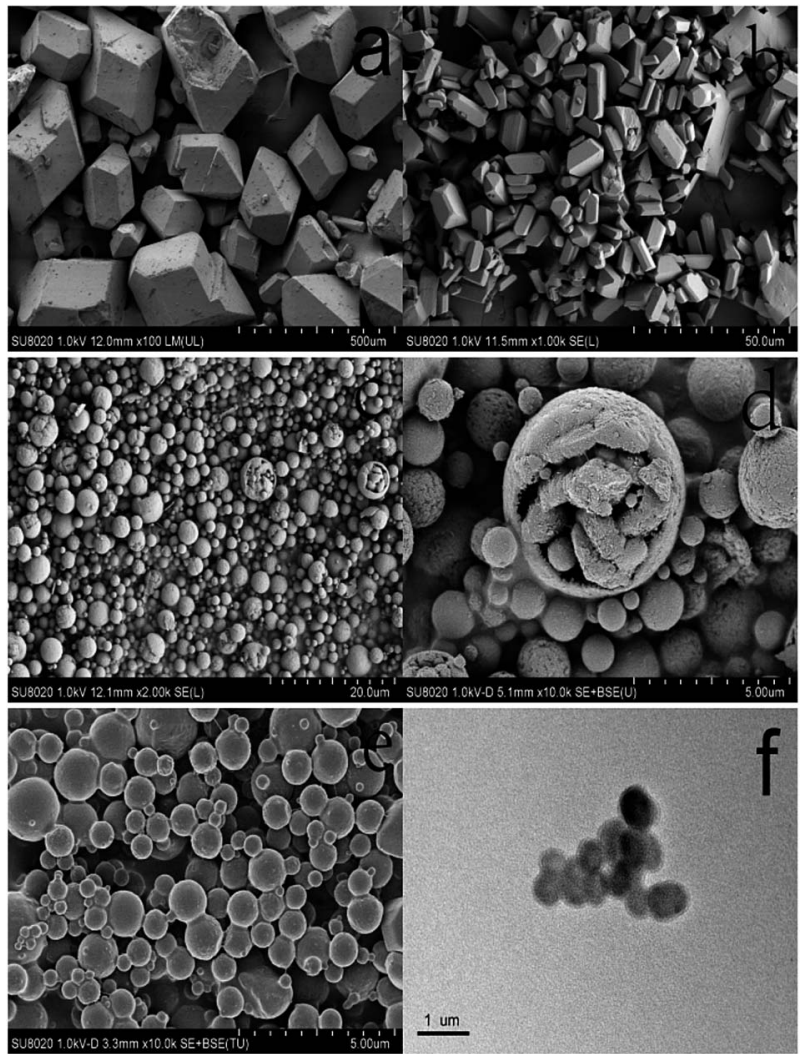

Fig. 2 SEM images of (a) raw HMX, (b) refined HMX, (c and d) sample-1 and (e) sample-2. TEM images of (f) sample-2.

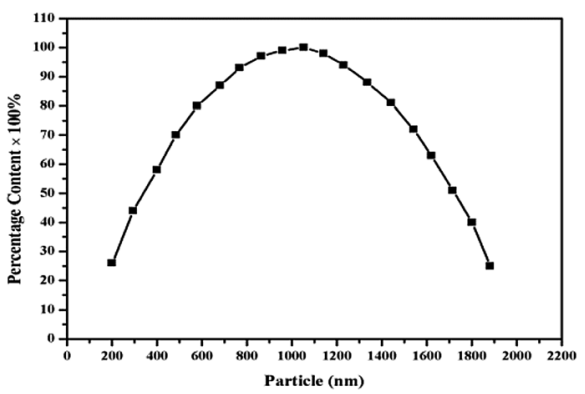

Fig. 3 Particle size distribution photograph of the sample-2.

images of raw and refined HMX. The refined HMX (Fig. 2b) act as columnar morphology with an average size of $\sim 10 \mu \mathrm{m}$ whose size and surface are smaller and smoother than that of raw HMX (100-300 $\mu \mathrm{m})$ shown in Fig. 2a. Sample-1 (Fig. 2c) are composed of many tiny particles that stick together to form a hollow microsphere. It is can be clearly seen from the magnified image shown in Fig. 2d. Fig. 2e reveals the micronscale morphology of sample-2. Different from the image of the sample-1, the hollow structure and collapsed microsphere disappear. From the TEM image shown in Fig. 2f, it can be finds that sample-2 are solid with core-shell structure. There is perfect spherical structure without the trace of GAP, suggesting GAP imbed in NC forming a composite binder. The particle distribution curve of the sample-2 is shown in Fig. 3. It is clear that the median particle size of the sample- 2 is $1 \mu \mathrm{m}$ and ranges from approximately $0.2 \mu \mathrm{m}$ to $1.5 \mu \mathrm{m}$, indicating a relatively narrow size distribution.

The different microstructure between sample-1 and samples2 is due to the different forming process of droplet resulting from the different dissolved form. In atomization process of preparing sample-2, HMX as the nucleus, binders could adhere to the surface of HMX after volatilizing of ethyl acetate to form a coating layer. In fact, the coating process in preparing sample2 is a physical process. The coating mechanisms of NC and GAP for HMX can be explained by the adsorption theory. The principle basis for adsorption theory is the intermolecular dispersion force between the binder and HMX. The binders dissolved in the ethyl acetate can be contacted with HMX and then NC and GAP gradually adsorbed HMX crystals due to intermolecular forces. The binders were coated on the surface of HMX and formed a continuous and dense cladding layer. Finally the HMX-based composite formed. However, in preparing sample1 , the formation is a mixing process rather than coating due to the co-solution of binders and HMX. The schematic illustration of the formation of sample- 1 and sample-2 is shown in Fig. 4.

\subsection{XRD analysis}

The obtained samples were characterized by using X-ray diffraction (XRD) and the results were shown in Fig. 5. The XRD pattern of raw and refined HMX, sample-2 and sample-3 display several typical diffraction peaks at $14.831^{\circ}, 16.178^{\circ}$, $20.629^{\circ}$ and $31.970^{\circ}$, correspond well with the crystal planes of

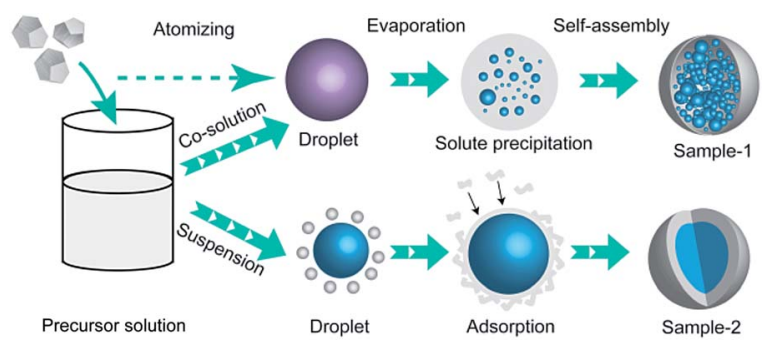

Fig. 4 Schematic illustration of the formation of sample-1 and sample-2.

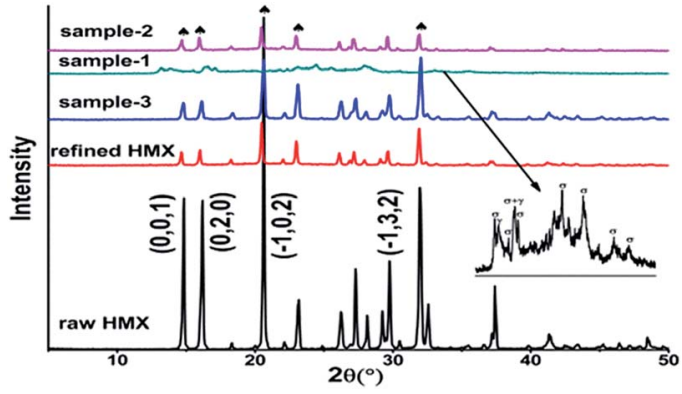

Fig. 5 XRD pattern of samples. The magnified spectrum of sample-1 is shown in the inset. 
$(0,1,1),(0,2,0),(-1,0,2)$ and $(-1,3,2)$ of $\beta$-HMX, indicating that the four samples acquired in the present work is $\beta$-form. However, the sample-1 exhibits unique non-overlapping diffraction peaks, which are attributed to $\gamma$-form and $\delta$-form, shown in the inset of Fig. 5. There is a peak broadening in sample-1 microspheres, due to the sample consists of many small HMX crystals with size below $500 \mathrm{~nm}$. The experiment of preparing sample-1 was repeated several times. However, the result is same. Thus there is needs a proper technology to control the crystal shape during co-solution spray drying, while the result using suspension is opposite. In preparing sample-2, there isn't exist dissolution and separate out of HMX. Thus, using suspension during spray drying is an effectively way to control the crystal form of explosives.

\subsection{FT-IR analysis}

FT-IR analyses were conducted to identify the molecular structure of the as-prepared samples, and the total spectra and regional spectra are displayed in Fig. 6. In the FT-IR spectra of NC, shown in Fig. 6a, there are characteristic bands at 1660 $\mathrm{cm}^{-1}, 1274 \mathrm{~cm}^{-1}, 1070 \mathrm{~cm}^{-1}, 833 \mathrm{~cm}^{-1}$, and $747 \mathrm{~cm}^{-1} / 681$ $\mathrm{cm}^{-1}$ corresponding to the vibration of $-\mathrm{O}-\mathrm{NO}_{2}, \mathrm{C}-\mathrm{N}, \mathrm{C}-\mathrm{O}$, carbon chain and $\mathrm{O}-\mathrm{NO}_{2}$, respectively. The bands at $2104 \mathrm{~cm}^{-1}$ and $1279 \mathrm{~cm}^{-1}$, shown in the spectrum of GAP, reflect the asymmetrical and symmetrical $-\mathrm{N}_{3}$ stretching in GAP. In addition, characteristic bands observed at $3437 \mathrm{~cm}^{-1}, 1350 \mathrm{~cm}^{-1}$, and $1127 \mathrm{~cm}^{-1}$ are attributed to $-\mathrm{OH}, \mathrm{O}-\mathrm{H}$, and $\mathrm{C}-\mathrm{O}$ vibrations

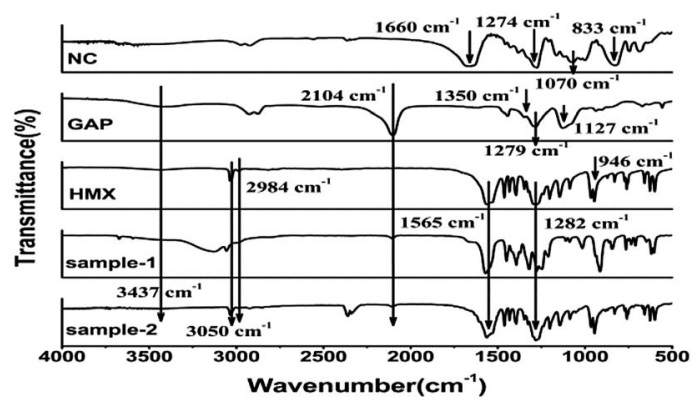

(a)

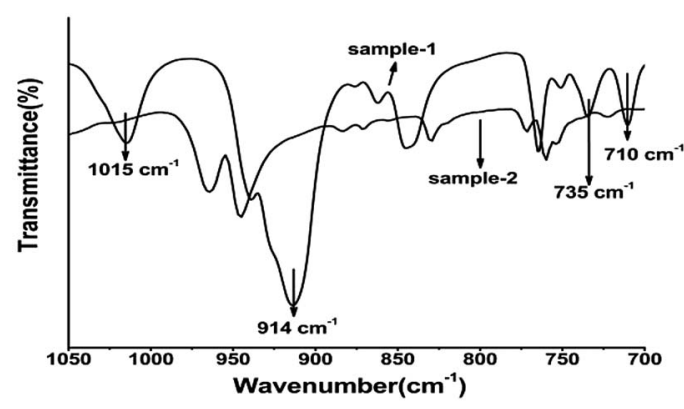

(b)

Fig. 6 FT-IR spectra of samples; (a) total FT-IR spectra, (b) regional FT-IR spectra from $1050 \mathrm{~cm}^{-1}$ to $700 \mathrm{~cm}^{-1}$. of GAP. The characteristic vibration peaks at $3050 \mathrm{~cm}^{-1}, 2984$ $\mathrm{cm}^{-1}, 1565 \mathrm{~cm}^{-1}, 1282 \mathrm{~cm}^{-1}$ and $946 \mathrm{~cm}^{-1}$ separately in HMX infrared spectrum are related to $-\mathrm{CH}_{3},-\mathrm{CH}_{2},-\mathrm{NO}_{2}, \mathrm{C}-\mathrm{N}-\mathrm{C}$ and the ring of HMX. In the spectrum of sample-2, the broad band located at about $3500 \mathrm{~cm}^{-1}$ is attributed to the stretching vibration of $-\mathrm{OH}$, which means that GAP is incorporated in sample-2. However, the characteristic peaks of the NC aren't apparently observed in $\mathrm{HMX} / \mathrm{NC} / \mathrm{GAP}$, which is mainly because that the characteristic bands of NC overlap the bands of HMX. Compared with the FT-IR spectrum of HMX, almost appearance of the vibration peaks are observed in the FT-IR spectrum of sample-2 indicating the molecular structure of HMX is not changed via the spray process. There are no characteristic adsorption peak ranges from $750 \mathrm{~cm}^{-1}$ to $700 \mathrm{~cm}^{-1}$ for $\beta$-HMX. However, in the spectrum of sample-1, there are four different absorption peaks at $710 \mathrm{~cm}^{-1}, 735 \mathrm{~cm}^{-1}, 914 \mathrm{~cm}^{-1}$ and 1015 $\mathrm{cm}^{-1}$, which corresponding to the characteristic adsorption peaks of $\gamma$-HMX and $\delta$-HMX, indicating the presence of $\gamma$-HMX and $\delta$-HMX. The result is consistent with the above conclusion.

\subsection{Thermal analysis}

Probing the thermal decomposition process was very important for energetic materials. Herein, DSC curves collected at a heating rate of $10{ }^{\circ} \mathrm{C} \mathrm{min}^{-1}$ were obtained in Fig. 7. In DSC curve of raw HMX (Fig. 7a), there is endothermic peak at $197.51{ }^{\circ} \mathrm{C}$ corresponding to crystal transformation of HMX from $\beta$-form to $\delta$-form. In the curve of sample-2, there is also a similar endothermic peak at $202.13{ }^{\circ} \mathrm{C}$. However, the curve of sample- 1 is different in that there is no endothermic peak presented. This is mainly because the sample- 1 isn't $\beta$-HMX. The result is consistent with that of XRD. In addition, the thermal decomposition process of NC and GAP were contrastively investigated by applying DSC, and the curves are shown in Fig. 7d and e. The endothermic melting peak of raw HMX in Fig. 7a disappears in sample- 1 and sample- 2 shown in Fig. $7 \mathrm{~b}$ and c. This situation may be because the melting peak is covered over with the decomposition peaks of NC and GAP. In the DSC curves of samples (including raw HMX, sample-1 and sample-2), there is one exothermic peak in each trace, which is attributed to the self-heating and autocatalytic of HMX. This may mean that they undergo similar decomposition process. The thermal decomposition temperatures of raw HMX, sample- 1 and sample- 2 are

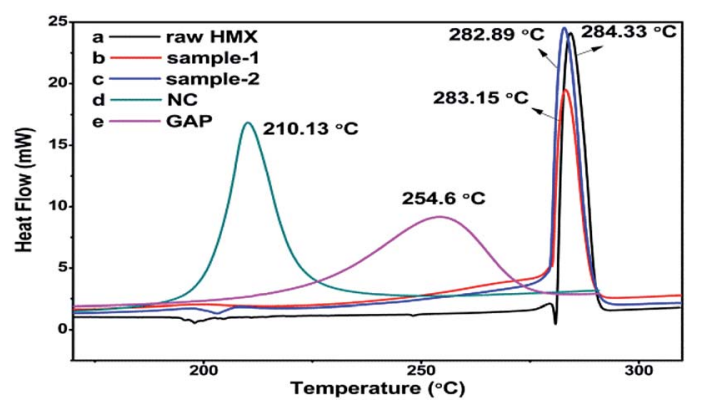

Fig. 7 DSC curves of samples collected at a heating rate of $10^{\circ} \mathrm{C}$ $\min ^{-1}$. 
$284.33{ }^{\circ} \mathrm{C}, 283.15{ }^{\circ} \mathrm{C}$ and $282.89{ }^{\circ} \mathrm{C}$ respectively, indicating that the three samples do not make obvious changes. The difference between raw HMX and HMX/NC/GAP microspheres is less than $2{ }^{\circ} \mathrm{C}$, implying that the binders of $\mathrm{NC}$ and GAP are compatible with HMX.

\subsection{Detonation performances}

The density and detonation parameters of samples including HMX, NC, GAP, HMX/NC/GAP, HMX/graphite, HMX/wax and RDX were calculated by EXPLO5 program for evaluating its energetic properties. As shown in Table 1, the detonation parameters of NC and GAP prove the high energy output. Though they are lower than that of HMX, they also higher than that of inert binders like graphite and wax. From the Table 1, it can be finds that the density and detonation performances of HMX are reduced because of the addition of NC and GAP, but they are still higher than those of RDX. ${ }^{24}$ In addition, the impact sensitivity of HMX was reduced greatly by NC and GAP, as will be discussed in Section 3.6.

\subsection{Impact sensitivity}

To investigate the safety performance of the samples, the test of the impact sensitivity was performed, and the results are presented in Table 2. It should be noted that the special height $\left(H_{50}\right)$ of samples is higher than that of raw HMX, probably because the binders NC and GAP are efficient absorber and diverter under the impact stimuli. As to sample-1 and sample-2, they can be concluded that significant desensitization effect has been achieved for the improved crystal morphologies and particle size distribution by spray drying, especially compared with sample-3 prepared by water-suspension method.

Table 1 Detonation performance of samples

\begin{tabular}{llccc}
\hline \multicolumn{3}{c}{ Detonation } & & \\
\cline { 2 - 5 } \multicolumn{1}{c}{ Samples } & $\begin{array}{c}\text { Density/ } \\
\mathrm{g} \mathrm{cm}^{-3}\end{array}$ & $\begin{array}{c}\text { Pressure/ } \\
\mathrm{GPa}\end{array}$ & $\begin{array}{c}\text { Temperature/ } \\
\text { K }\end{array}$ & $\begin{array}{c}\text { Velocity/ } \\
\mathrm{m} \mathrm{s}^{-1}\end{array}$ \\
\hline HMX & 1.91 & 38.87 & 3687.74 & 9234.74 \\
NC & 1.65 & 21.96 & 3204.97 & 7341.01 \\
GAP & 1.29 & 12.80 & 2669.86 & 6645.78 \\
HMX/NC/GAP & 1.88 & 37.40 & 3671.34 & 9102.85 \\
HMX/graphite & 1.91 & 37.10 & 3551.16 & 9087.35 \\
HMX/wax & 1.83 & 34.55 & 3544.01 & 8977.57 \\
RDX & 1.80 & 34.27 & 3815.21 & 8837.82
\end{tabular}

Table 2 Impact sensitivity of HMX before and after coating

\begin{tabular}{llll}
\hline Samples & Methods & Contents/\% & $H_{50} / \mathrm{cm}$ \\
\hline Raw HMX & - & HMX (100) & 19.6 \\
Sample-1 & Co-solution spray drying & HMX/NC/GAP (95/3/2) & 46.9 \\
Sample-2 & Suspension spray drying & HMX/NC/GAP (95/3/2) & 56.0 \\
Sample-3 & Water-suspension & HMX/NC/GAP (95/3/2) & 34.4
\end{tabular}

In theory, "hot spots" were formed when explosive charges underwent an extrinsic stimulation, such as impact, fraction and shock wave, et al. The properties of the generation, growth and spreading of hot spots determined the difficulty of the explosion. In explosive charges, the tiny pores and voids were subjected to adiabatic compression, which resulted in a very fast elevation of the temperature inside the pores. ${ }^{25}$ When the temperature exceeded the critical temperature, "hot spots" formed. The impact sensitivity of sample-2 $\left(H_{50}=56.0 \mathrm{~cm}\right)$ can be reduced as compared with sample-1 $\left(H_{50}=46.9 \mathrm{~cm}\right)$, attributing to the compact and uniform coating of NC and GAP binders on the surface of HMX. When it underwent an external impact action, the binders shell would be firstly attacked as a buffer system to dissipate the impact energy. However, sample-1 is composed of many small microspheres. There are many tiny pores and voids exist. Once an external impact action occurred, the tiny pore and voids can assist the formation of "hot spots", igniting the surrounding materials and leading to detonation. ${ }^{26}$ These results demonstrate that such a core-shell coating via spray drying of suspension provides an efficient route for decreasing mechanical sensitivity.

\section{Conclusions}

Herein, HMX/NC/GAP was prepared successfully by spray drying process. Compared with raw HMX, sample-1 prepared by co-solution spray drying, sample-3 prepared by water suspension, the sample-2 prepared by suspension spray drying have a unique core-shell structure and narrow particle size distribution of $0.2-15 \mu \mathrm{m}$. In the process of preparing sample-2, the HMX maintains the $\beta$-form, while the sample- 1 is opposite. This means that the suspension spray drying is an effective method to keep the original crystal form of explosive. From the results of thermal analysis, the similar decomposition process indicates that sample-2 keeps the thermal stability of HMX. The difference between raw and HMX/NC/ GAP microspheres is less than $2{ }^{\circ} \mathrm{C}$, proving that the binders, NC and GAP, are compatible with HMX. Sample-2 maintains the excellent energetic properties with the detonation pressure and detonation velocity as $37.402 \mathrm{GPa}$ and $9102.849 \mathrm{~m} \mathrm{~s}^{-1}$. In addition, the mechanical sensitivities of sample-2 $\left(H_{50}=56.0 \mathrm{~cm}\right)$ are lower than that of other samples. Therefore, with good combination energy performance with safety, the new HMX-based microspheres of $\mathrm{HMX} / \mathrm{NC} / \mathrm{GAP}$ are very suitable as the main ingredient in a propellant.

\section{Acknowledgements}

This work was supported by the Advantage Disciplines Climbing Plan of Shanxi Province, the 13th Graduate Students of Science and technology in North University of China (No. 20161325) and Graduate Education Innovation Project in Shanxi Province (No. 2016BY119). 


\section{References}

1 R. L. Simpson, P. A. Urtiew, D. L. Ornellas, G. L. Moody, K. J. Scribner and D. M. Hoffman, Propellants, Explos., Pyrotech., 1997, 22, 249.

2 A. E. D. M. Van der Heijden and R. H. B. Bouma, Cryst. Growth Des., 2004, 4, 999.

3 D. M. Hoffman, J. Energ. Mater., 2000, 18, 1.

4 Z. J. Yang, L. Ding, P. Wu, Y. G. Liu, F. D. Nie and F. L. Huang, Chem. Eng. J., 2015, 268, 60.

5 A. A. Dippold and T. M. Klap ke, J. Am. Chem. Soc., 2013, 135, 9931.

6 Y. Ma, A. B. Zhang, C. H. Zhang, D. J. Jiang, Y. Q. Zhu and C. Y. Zhang, Cryst. Growth Des., 2014, 14, 4703.

7 Z. G. Ma, B. Gao, P. Wu, J. C. Shi, Z. Q. Qiao, Z. J. Yang, G. C. Yang, B. Huang and F. D. Nie, RSC Adv., 2015, 5, 21042.

8 B. Gao, D. J. Wang, J. Zhang, Y. J. Hu, J. P. Shen, J. Wang, J. B. Huang, Z. Q. Qiao, H. Huang and F. D. Nie, J. Mater. Chem. A, 2014, 2, 19969.

9 A. Elbeih, S. Zeman, M. Jungová and P. Vávra, Propellants, Explos., Pyrotech., 2013, 38, 378.

10 P. D. Peterson and D. J. Idar, Propellants, Explos., Pyrotech., 2005, 30, 88.

11 M. M. Jin, G. Wang, J. K. Deng, G. P. Li, M. H. Huang and Y. J. Luo, J. Sol-Gel Sci. Technol., 2015, 76, 58.

12 W. Ji, X. D. Li and J. Y. Wang, Cent. Eur. J. Energ. Mater., 2015, $12,831$.
13 W. Ji, X. D. Li, J. Y. Wang, B. Y. Ye and C. L. Wang, J. Energ. Mater., 2016, 34, 357.

14 C. W. An, H. Q. Li, X. H. Geng, J. L. Li and J. Y. Wang, Propellants, Explos., Pyrotech., 2013, 38, 172.

15 X. F. Shi, J. Y. Wang, X. D. Li and C. W. An, Cent. Eur. J. Energ. Mater., 2014, 11, 433.

16 X. F. Shi, J. Y. Wang, X. D. Li, C. W. An and W. Ji, Def. Sci. J., 2015, 65, 131.

17 H. W. Qiu, V. Stepanov, R. Anthony, D. Stasio, A. Surapaneni and W. Y. Lee, Powder Technol., 2015, 274, 333.

18 B. Y. Ye, C. W. An, J. Y. Wang, H. Q. Li, W. Ji and K. Gao, J. Propul. Power, 2016, 32, 1035.

19 X. F. Shi, J. Y. Wang, X. D. Li and C. W. An, J. Propul. Power, 2015, 31, 757.

20 C. W. An, F. S. Li, J. Y. Wang and X. D. Guo, J. Propul. Power, 2012, 28, 444.

21 G. P. Li, M. H. Liu, R. Zhang, L. H. Shen, Y. Z. Liu and Y. J. Luo, Colloid Polym. Sci., 2015, 293, 2269.

22 A. K. Nandi, M. Ghosh, V. B. Sutar and R. K. Pandey, Cent. Eur. J. Energ. Mater., 2012, 9, 119.

23 L. Yu, H. Ren, X. Y. Guo, X. B. Jiang and Q. J. Jiao, J. Therm. Anal. Calorim., 2014, 117, 1187.

24 Z. M. Li, Y. Q. Zhang, L. Liu and S. J. Zhang, RSC Adv., 2015, 5, 98925.

25 Y. Wang, X. L. Song, D. Song, L. Liang, C. W. An and J. Y. Wang, J. Hazard. Mater., 2016, 312, 73.

26 N. K. Bourne, Shock Waves, 2002, 11, 447. 